\title{
EDITORIAL DE FECHAMENTO DO VOLUME 10, 2020
}

O ano de 2020 marcou o segundo ano de adoção do sistema de publicação Fluxo Contínuo pela revista $D R d$ - Desenvolvimento Regional em debate. A partir da experiência do primeiro ano (2019), qualificamos o processo editorial e procuramos avançar, ampliando o número de artigos publicados a cada ano, bem como, a abrangência nacional e internacional da revista.

Assim, no Volume 10, no ano de 2020, foram publicados 63 (sessenta e três) artigos, perfazendo 1.428 (um mil e quatrocentos e vinte e oito) páginas, além de 3 (três) resenhas de livro, somando mais 14 (quatorze) páginas. Nos artigos, colaboraram 183 (cento e oitenta e três) autores e, nas resenhas, mais 5 (cinco).

Tomando como variável as palavras-chave, a categoria teórica desenvolvimento foi referenciada 49 (quarenta e nove) vezes no conjunto dos artigos, sendo somente desenvolvimento 5 (cinco), desenvolvimento sustentável 6 (seis), desenvolvimento regional 25 (vinte e cinco), desenvolvimento rural 7 (sete), desenvolvimento socioeconômico 2 (duas), desenvolvimento local 2 (duas) e desenvolvimento territorial 1 (uma) menção. Isso demonstra que em mais de $82 \%$ dos artigos, a categoria desenvolvimento foi utilizada, o que converge fortemente com o foco temático da revista DRd.

Na sequência, a categoria região foi citada 7 (sete) vezes diretamente e mais 25 (vinte e cinco), referenciando um determinado recorte regional. Ademais, os termos agricultura e agricultura familiar foram referenciados nas palavras-chave 14 (quatorze) vezes de forma direta e mais 12 (doze) em outras categorias convergentes com o tema rural.

Outros temas são recorrentes, tais como, as questões ambientais 15 (quinze) menções, políticas públicas 12 (doze), território, quatro (4), além de outras, como cadeias produtivas, cooperativas, participação, solidariedade, cidadania e questões sociais, cooperativismo, turismo, desigualdades regionais, questões urbanas, economia e indicadores socioeconômicos e de desenvolvimento, energia limpa, gestão pública, social e empresarial, saúde, mudanças climáticas, planejamento regional, alimentação e sistemas agroalimentares, trabalho, questões relacionadas à metodologias e muitos outros.

Portanto, por esta amostra de categorias teóricas que aparecem nas palavras-chave e os temas abordados nos artigos, pode-se considerar que a revista DRd tem forte aderência ao foco temático a que se propõe tratar nos seus objetivos.

Outra variável que confirma a convergência com o escopo teórico da DRd, são os títulos dos artigos, conforme relacionados abaixo:

-(Des)envolvimento regional, fronteira e o espaço do agronegócio no Tocantins: crescimento econômico sem distribuição de renda;

-Impactos socioeconômicos do complexo eólico Canoas e Lagoas a partir da percepção da comunidade local; 
-O mercado de chocolate no sul da Bahia: estrutura, produção e comercialização;

-O caso da Cooperativa de Trabalho de Costureiras Unidas Venceremos: relatos de uma experiência de economia solidária;

-Diversidade de sistemas produtivos e sustentabilidade na agricultura;

-Distância para a cidadania na Bahia: o acesso aos documentos certificadores sob a ótica de Christaller;

-Os pêssegos não caem do céu: relações de trabalho e agricultura familiar na região de Pelotas-RS;

- A criação do Banco do Nordeste e o Congresso Nacional: momento de disputa inter e intra elites ou de consenso regional?;

-Determinantes do crédito: uma análise do Programa Nossocrédito do Espírito Santo de 2013 a 2015;

-Simulações para produzir soja de forma sustentável na região do Matopiba;

-Análise dos impactos socioambientais na zona costeira do município de Salinópolis/PA;

-Vulnerabilidades induzidas no Semiárido Brasileiro;

- Análise comparativa de lucratividade das culturas de erva-mate em relação a soja no Planalto Norte Catarinense;

-Usos exploratórios e sustentáveis da natureza no entorno do Parque Nacional da Serra do Itajaí em Indaial-SC;

-Perfil de conduta econômica, ambiental e social: um estudo em uma indústria metal mecânica;

-Mudanças climáticas, comércio intranacional e exportações agrícolas à luz do modelo gravitacional: estimativas para o nordeste brasileiro;

-Neoliberalismo e desenvolvimento regional: obstáculos da política regional no Brasil

-Indicadores de sustentabilidade socioeconômica do desenvolvimento rural no município de Rolante/RS;

-Processos de metropolização latino americanos: o caso de São Paulo vis a vis o de outras experiências;

-Impactos socioeconômicos do setor sucroenergético na Paraíba: uma análise com dados em painel para 2005-2016; 
- Análise multidimensional da desigualdade socioeconômica no Rio Grande do Norte - 2000/2010;

-Tomada de decisão pela diversificação: uma alternativa para agricultura familiar na microrregião de Santa Cruz do Sul/RS;

-Aquisições da agricultura familiar e qualidade dos alimentos fornecidos na rede escolar municipal de Catuípe/RS;

-Indicadores de resiliência a riscos e desastres: instrumentos globais para o enfrentamento de eventos extremos;

-Desenvolvimento regional do sudeste do Pará baseado na aplicação do índice de desenvolvimento regional;

-Produção de soja, desigualdades no campo e mudanças climáticas na região do Matopiba;

-Análise e planejamento municipal aplicado: um exercício para o caso de Palmeira das Missões/RS;

-Quais as potencialidades e entraves para o programa nacional de alimentação escolar em Getúlio Vargas/RS?;

-Ferrovia norte-sul: impactos no desenvolvimento de Açailândia e Porto Nacional;

-Para além da educação e da pesquisa: a interação da universidade pública com a sociedade;

-O trabalho das mulheres na pecuária leiteira: análise em contextos de produção modernos, tradicionais e em transição no Rio Grande do Sul (Brasil);

-Análise da política de incentivos fiscais municipal: o caso de Osório/RS: repercussões e propostas;

-Gestão social comparada: territórios da APA Cantão e Bico do Papagaio no Tocantins;

-A relação estado e terceiro setor no Brasil: elementos basilares e premências investigativas;

-PRONAF no estado do Paraná: quais lógicas de desenvolvimento têm sido fortalecidas?;

-A atuação profissional de enólogos do IFRS campus Bento Gonçalves no enoturismo brasileiro;

-Análise técnico-social da produção de biodiesel no Brasil e no desenvolvimento agrícola do norte de Minas Gerais; 
-Pobreza monetária no Brasil, urbana e rural, de 2012 a 2018;

-Política pública do biodiesel no Brasil: uma análise na perspectiva do ciclo das políticas públicas;

-Energia solar como fator de desenvolvimento rural e a produção de leite em Goiás;

-Saúde e vulnerabilidade social: discutindo a necessidade de ações comunitárias com base em indicadores sociais no município de Taquara/RS;

-Estudo sobre a dinâmica econômica do município de Taquara/RS referenciada na metodologia do quociente locacional;

-Relevância econômica dos benefícios previdenciários nos municípios da região COREDE Celeiro/RS;

-Estratégias de gestão de uma cooperativa de crédito resultantes da avaliação econômica e financeira (2013 a 2017);

-Práticas contábeis e a accountability em universidades comunitárias no Rio Grande do Sul;

-Vulnerabilidade socioeconômica no semiárido cearense: um estudo a partir das mesorregiões do estado;

-Evolução das despesas públicas em políticas sociais na região funcional 7 e impactos no IDESE;

-Perspectivas de desenvolvimento no semiárido: um estudo sobre os impactos iniciais do canal do sertão na realidade dos produtores rurais alagoanos;

- Caracterização espacial da modernização agrícola dos municípios do estado do Rio Grande do Sul (2010 e 2017);

-Desafios do programa de aquisição de alimentos (PAA) em fomentar autonomia de agricultores familiares;

-Entidades de mediação e constituição de parcerias institucionais locais: uma reflexão a partir do Famalicão made in, Portugal;

-Comunicação de risco de inundação: instrumento fundamental da gestão de riscos de desastres;

-Lauro de Freitas no contexto do turismo da região metropolitana de Salvador: um centro turístico dormitório?;

-A reconversão de regiões carboníferas na Europa: aplicação do lock in por Grabher em casos selecionados; 
-Impactos do sistema de pagamento por qualidade do leite em uma cooperativa da agricultura familiar;

-Educação ambiental e intervenção na microbacia do Lajeado Sabão, em Concórdia$\mathrm{SC}$;

-Desoneração tributária como fator de desenvolvimento socioeconômico das regiões brasileiras;

-Integrando a agricultura urbana e periurbana em políticas de planejamento urbano;

-Confiança e sustentabilidade social: um estudo em cooperativas de materiais recicláveis;

-Impacto do El Niño oscilação sul (ENOS) e da el Niña no mercado da soja brasileira;

- A participação da agricultura familiar nas compras para a alimentação escolar do rio grande do sul: uma análise segundo a regionalização dos COREDES;

-Desigualdades socioeconômicas no Brasil: dinâmicas territoriais no urbano e no rural.

-Planejamento regional e pandemia: o modelo de distanciamento controlado do Rio Grande do Sul.

Em 2020, além dos artigos e resenhas, já referidos, com suas temáticas centrais, a revista DRd também publicou um Dossiê Temático, cujo tema foi: Conhecimento, inovação, criatividade e inteligência para o desenvolvimento de cidades, municípios, regiões ou territórios. O dossiê foi constituído de 11 (onze) artigos, perfazendo 292 (duzentos e noventa e duas) páginas. Todos os artigos trataram de temas que convergem com a temática da inovação e o desenvolvimento (local, regional, territorial). Os diferentes enfoques tratados, pode ser melhor percebido, se observados os títulos dos artigos:

-Ciência e inovação na consecução de municípios inteligentes para o desenvolvimento local sustentável;

-Cidades inteligentes e criativas e smartificação dos territórios: apontamentos para reflexão;

-Análise de brandings urbanos contemporâneos na ótica da sustentabilidade: abordagens centrais, potencialidades e limitações;

-Oeiras smart: um learning case de inteligência territorial;

-Inclusão sociocultural diferenciada da juventude nos novos modelos de desenvolvimento urbano: Medellín cidade digital;

-Incorporação e desenvolvimento de tecnologias de informação em cidades Argentinas: uma análise de caso; 
-Análise da inserção de cidades no movimento Slow City como diretriz de qualificação e inovação territorial;

-O lado humano das cidades inteligentes e o contributo do empreendedorismo social;

- Aplicativo WEBSIG na localização de recursos comerciais para o SICOM de Chapecó (SC-Brasil);

-Governança e gestão inteligentes em municípios de pequeno porte: o caso de Luzerna (SC - Brasil);

-Gestão estratégica integrada do transporte público de passageiros e suas relações com cidade digital estratégica.

Essa foi a produção editorial da revista Desenvolvimento Regional em debate no ano de 2020, cuja avaliação pode ser considerada altamente positiva.

O ano de 2021 marcará os primeiros 10 (dez) anos de edição da revista DRd. A caminhada editorial desta primeira década será marcada, também, por novos avanços, com destaque para três deles: (i) pelo sistema Redalyc, a revista DRd poderá ser acessada em diferentes linguagens de leitura (PDF, HTML, E-PUB); (ii) além dos artigos a serem publicados no sistema Fluxo Contínuo, que comporá o Volume 11, a DRd publicará dois dossiês, um no primeiro semestre tratando de um tema universal, previamente definido, e outro no segundo semestre, versando sobre temas regionais, de uma das regiões brasileiras, tarefa que terá a contribuição especial de editores convidados; (iii) a DRd terá uma renovação significativa na sua Equipe Editorial, contando, além dos Editores (geral e adjunto), com 8 (oito) Editores Associados, representando oito Programas de Stricto Sensu, de 8 (oito) universidades brasileiras. O Corpo Editorial Científico passará a contar com 25 (vinte e cinco) membros, sendo que destes, 18 (dezoito) serão internacionais, oriundos de países da América, Europa, África e Ásia. Ademais, a equipe de Revisores ad hoc contará com mais de 380 (trezentos e oitenta) pesquisadores nacionais e internacionais.

A opção pela contribuição de editores convidados, representando oito programas de Stricto Sensu de universidades brasileiras, tem como propósito ampliar a capilaridade da revista DRd junto a programas de Mestrado e Doutorado que tenham como tema central de estudos, as questões regionais, com isso, aprofundando o debate sobre desenvolvimento regional no Brasil. Cabe destacar que as mudanças na Equipe Editorial têm outro propósito: avançar na internacionalização, tanto na publicação de artigos, quanto na representatividade dos membros do Corpo Editorial Científico e dos Revisores ad hoc.

Com isso, pretende-se consolidar a revista Desenvolvimento Regional em debate, em nível nacional e internacional, dentre os periódicos que fomentam o debate sobre questões regionais/territoriais, relacionadas ao processo de desenvolvimento.

Santa Catarina (Brasil), dezembro de 2020.

Valdir Roque Dallabrida - Editor Geral - DRd Alexandre Assis Tomporoski - Editor Adjunto - DRd Josiane Liebl Miranda - Editoração - DRd Gabriel Bonetto Bampi - Pró-Reitor da UnC

DRd - Desenvolvimento Regional em debate (ISSNe 2237-9029) 